\title{
Research of Copper Alloys-nickel Composites by Laser Direct Writing
}

\author{
Tao WANG ${ }^{1.2}$, Ya-Peng $\mathrm{HU}^{1.2}$, Xin-Chao ZHAO ${ }^{1.2}$, Jin-Long ZHU ${ }^{1.2}$, \\ Fu-Zeng $\mathrm{LI}^{1.2}$, Zhan-Hua ZAN ${ }^{1.2}$, Long-Fei MA ${ }^{1.2}$ \\ 1. Hebei University of Technology, College of Mechanical, Tianjin 300130 \\ 2. Nanjing Jin Song Han Power technology co., LTD, Jiangsu Nanjing 211316
}

Key words: Copper Alloys-nickel Composites, Vapor deposition, liquid phase reaction deposition, laser-cladding, Laser cladding copper nickel alloy

\begin{abstract}
For the purpose of solve seawater pipe's anti-corrosion materials problem and it is all of varieties, this thesis come up with the copper alloys-nickel composites by Laser direct writing and the method's application and equipment, this thesis also recommend the copper alloys-nickel composites' laser chemical vapor deposition, laser induced liquid deposition, and laser cladding prototyping. To avoid laser cause excess damage to the copper alloys-nickel composites, coating a layer of film of heat actuable adhesive on the basal plate, then pave a layer of copper alloys-nickel composites powder, after rolling use laser heat activate adhesive film, copper alloys-nickel composites used for seawater pipe prepared by laser cladding on copper alloys-nickel composites basal plate. On the copper alloys-nickel composites basal plate laser cladding copper alloys-nickel composites used for seawater pipe anti-oxidation copper nickel alloy layer. Research of laser micro-cladding copper alloys-nickel composites' equipment parameter and optimize, use the copper powder and nickle powder make cupronickel and use the thermosetting resin as adhesive system can make copper alloys-nickel composites on the seawater pipe basal plate, the accuracy is $20 \mu \mathrm{m}$, the minimum width can under $80 \mu \mathrm{m}$.
\end{abstract}

\section{Summarize}

Nowadays copper alloys-nickel composites pipe is the best seawater corrosion resistant material, seawater pipe use copper alloys-nickel composites pipe usually, the B10 or B30 whose characters are good anticorrosion property, wide application, and styles are all of varieties are in common use. So this thesis comes up with the copper alloys-nickel composites' laser cladding manufacturing technology and equipment used for seawater pipe, achieved manufacture copper alloys-nickel composites on a large-scale and diversifiedly.

Copper alloys-nickel composites used for seawater pipe develop in large scale integration, digitization and diversification.Using direct manufacturing based on laser cladding technology instead of using molds, Core technology is copper alloys-nickel composites made by laser-cladding technology, achieved copper alloys-nickel composites' diversification and integration, reduce production cost.

Research for copper alloys-nickel composites, use laser-cladding copper alloys-nickel composites, achieved minimum pipe width and maximum surface area, laser beam has characters like high energy density, precision flare, avoid the effect of electromagnetic field, high position accuracy and so on.

Laser direct writing includes laser chemical vapor deposition technology, laser induced liquid deposition technology, laser sintering rapid prototyping technology and solid state membrane laser induce copper alloys-nickel composites deposition called laser cladding. Above mentioned called laser direct writing. 


\section{Laser Deposition}

\subsection{Laser Chemical Vapor Deposition-LCVD}

LCVD is a process which uses laser beam heat or High-energy effect induced chemical reaction deposition film[1]. When the laser beam scans on the basal plate by a fixed path, needed copper alloys-nickel composites can be deposition on the basal plate, finish the molding task. Using LCVD deposition copper alloys-nickel composites on the basal plate can produce copper alloys-nickel composites pipe on copper alloys-nickel composites substrate.

LCVD method's production have high density of copper alloys-nickel composites, dense structure, the pipe has narrow pipe diameter, the minimum can reach $2 \mu \mathrm{m}$, speed of molding is 90 $\mathrm{mm} \cdot \mathrm{s}^{-1}$.Density of copper alloys-nickel composites can be easily controlled, so can achieved manufacture copper alloys-nickel composites on a large-scale and diversifiedly.

\subsection{Laser Induced Liquid Phase Deposition}

Laser induced liquid phase deposition is on the base of LCVD, preset crystal seed by laser, laser irradiate basal plate directly, manufacture copper alloys-nickel composites on the basis plate, the minimum can reach $2 \mu \mathrm{m}$ too.

\section{Copper Alloys-nickel Composites Manufacture and Molding by Laser Direct Writing}

Different from the LCVD and laser induced liquid phase deposition which main depend on atoms deposition, molding by laser direct writing use solid particle of copper-nickel alloy or other compound and bond strength of composite mix and put them on the basis plate first, after laser heat, the solid particle deposition on the basis plate, so it can deposition rapidly. Use copper-nickle powder and bond strength of composite mix on the copper-nickel alloy with copper substrate, use CO2 laser irradiate make the copper-nickle powder estore, form the copper-nickel alloy, achieved cladding alloy on the copper substrate. Molding by laser direct writing need higher temperature and keep long time, driven the copper-nickel alloy powder revert to copper-nickel alloy particle, the technological parameters should be controlled properly to avoid laser over damage the copper-nickel alloy. Coating a layer of film of heat actuable adhesive on the basis plate first, and then use laser heat the film and active it, bond the copper-nickel alloy and the basis plate, then use brush and leaner clean the powder on the non-irradiated area, form the copper-nickel alloy shape, last sintering in the furmace, form slippy copper-nickel alloy. The speed of copper-nickel alloy by laser direct writing can reach $2.5 \mathrm{~mm} \cdot \mathrm{s}^{-1}$.Preset the copper-nickel alloy in a proper precision by roll, after laser irradiating decomposes out copper-nickel alloy particle, the minimum width of the pipe can reach about $1 \mathrm{~mm}$, increase the laser power step by step control the decompose speed of copper-nickel alloy, the maximum speed is about $5 \mathrm{~mm} \cdot \mathrm{s}^{-1}$.

To solve the problem that it is easy to generate fold and pore, use the mixed copper-nickel alloy salt and amide put on the basal body[3], for the copper-nickel alloy formed after laser irradiate, in the centigrade degree $(\mathrm{t})=100^{\circ} \mathrm{C}$, the Curie temperature $\left.\mathrm{Tc}\right)=310 \mathrm{~K}$, the pipe spacing is $5 \sim 60 \mathrm{~mm}$, pipe width is $1 \sim 30 \mathrm{~mm}$, the maximum speed of molding can reach $90 \mathrm{~mm} \cdot \mathrm{s}^{-1}$; Take the advantage of laser irradiation partition, make it sticky roll and coating copper-nickel alloy powder again, form the copper-nickel alloy shape, last keep abuot 10 minutes in the $850^{\circ} \mathrm{C}$ condition, get the luminant copper-nickel alloy in $30^{\mu \mathrm{m}}$ precision. Use micro nozzle coat Ultrafine copper nickel alloy powder in the crack of copper-nickel alloy, after laser direct writing reconnect it. Put the mixed nanopowder and chemical precursor on the basis plate, use laser sintering manufacture copper-nickel alloy, pipe, and so on. Use preseted abnormity of rare earth copper nickel alloy on the heat resisted copper-nickel alloy basis plate, take advantage of $\mathrm{Nd}$ : YAG laser obtain rare earth copper nickel alloy, after heat and sintering, format the pipe in $60 \sim 230 \mathrm{~mm}$ pipe width. Laser direct writing can manufacture narrow pipe width copper-nickel alloy pipe flexibly without mould, and influence little to the environment. 


\section{Copper Nickel-alloy Manufactured by Laser Direst Writing}

\subsection{Laser Direct Write the shape of Copper Nickel alloy on Copper Nickel-alloy Basis Plate}

Use copper powder and nickle powder manufacture copper nickle alloy with hermosetting resin be the cementation system, can manufacture copper nickle alloy on the basis plate used for seawater pipe, the precision can reach $20^{\mu m}$, the minimum width can under $80^{\mu m}$, improve the performance[4].Copper nickel alloy magnetic ring made by laser direct writing like figure1.1

\subsection{Laser Direct Write Copper Nickel alloy on Copper Alloys-nickel Composites and Alloys-nickel Basis Plate}

Use magnetic powder of copper and nickel alloy with copper nickel material of low melting point like copper nickel serious powder, can molding on the copper and nickel basis plate, the copper nickel-alloy manufacture on it has the characters like strong adhesive force, high Performance, high density.

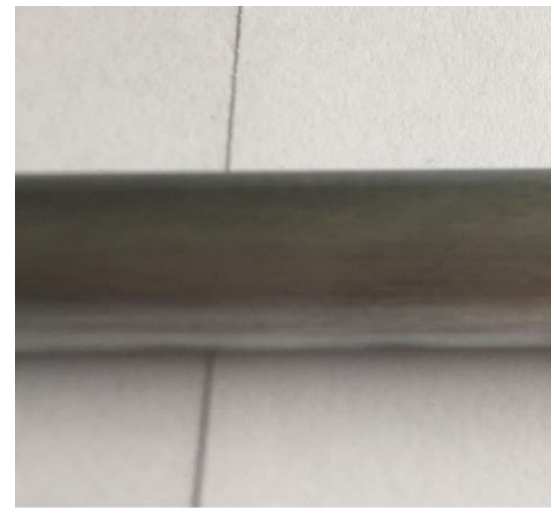

Fig.1 Pipe manufactured by laser direct writing

The picture of real products manufactured on the basis plate like figure1.2, the minimum width of pipe can reach $40^{\mu m}$, the minimum tube pitch can reach $30^{\mu m}$.

Use copper be the slurry system of copper nickle alloy, can manufacture continuous, even copper nickle alloy, the binding force between copper nickle alloy and the basis plate is strong, magnetism of copper nickle alloy is better than the copper nickle alloy made in traditional way[5], and so does the minimum width of pipe[6].

\subsection{Small Scale Production of copper Nickle Alloy}

Laser direct writing can speed up the development of research for the copper nickle alloy used for seawater pipe, can manufacture copper nickle alloy board in limited quantities directly. Copper nickle alloy made by laser don't need mould, equipment is simple to put in the office and laboratory, designer can tun the shape of copper nickle alloy into real copper nickle board keep indoors. Laser direct writing has the characters of convenient and rapid.

Laser direct writing can also used for the rapid manufacture of tube sheet and heteromorphism copper nickle. When using the argon ion laser, the minimum facula can below $5^{\mu m}$ [7], the advantage can made the width of copper nickle alloy and tube pitch reach the same order of magnitudes, get rid of the limit of traditional moulding techniques and improve the pipe reach the minimum size, decrease the pipe size about 10 times, so the overall dimension decreased too, improved the quality of the pipe and save the raw material.

Take advantage of laser direct writing can repair and remanufacturing the heteromorphism copper nickle alloy efficiently rapidly.

\subsection{Range of Application of copper Nickle Alloy}

By laser direct writing can manufacture kinds of copper nickle alloy for seawater pipe on the basis plate, include cladding antioxidation coating on the copper nickle layer, like Fig.2, control the shape 
and length of copper nickle alloy by laser direct writing, manufacture the designed copper nickle alloy. Using this method can manufacture tubular copper nickle alloy, spiral copper nickle alloy, flakiness copper nickle alloy and so on.

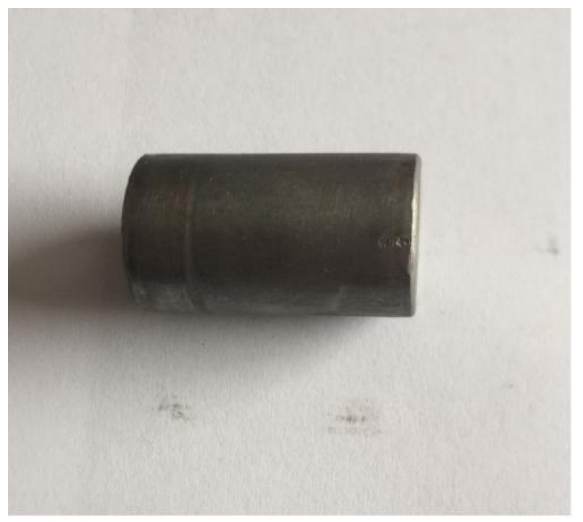

Fig.2 Antioxidation coating sleeve by laser direct writing

\section{Methods and Equipments used for Laser Direct Writing copper Nickle Alloy}

Develop the molding software for laser direct writing, use the copper nickle alloy particle and thermosetting resin as the cladding material, use the seawater pipe as the basis plate, use $\mathrm{CO}_{2}$ laser heating, manufacture copper nickle alloy directly. Build the temperature field model of micro cladding, drive the quantitative formula for calculating of laser power and laser scanning speed, forecast the laser parameter of form the rated pipe width of copper nickle alloy in the micro cladding process. Connect ytterbium doped fiber laser with erbium ytterbium doped fiber laser [8], achieved the research for $532 \mathrm{~nm}$ trigger and $1537 \mathrm{~nm}$ trigger switching oscillating. Build the physical and mathematical models for power-feeding laser cladding, according to the mathematical model and the temperature field, discussed the energy redistribution when parameters of cladding changed. Use RCDF in the 3D dynamic focusing laser galvanometer scanning, eliminate the principal error of X-Y dual galvanometer scanning, reduce the scanning spot distortion in the scanning process, optimize the scanning algorithm, improve the efficiency of scanning sintering.

In the sediment process, use a input equipment for receiving the powder and a output equipment for sending the waste powder form a small 3D cladding equipment, use laser direct writing manufacture copper nickle alloy permanent magnet material, build the temperature and pressure molding about time and space in the laser cladding process, optimize the test.

The laser direct writing equipment for copper nickle alloy consists of laser device for laser direct writing, cooling system, optical system for laser direct writing, scanning system, CNC three-dimensional workbench.

Optimization for the path of laser micro cladding workpiece, when locate the workpiece on the 2D plane of the CNC XY table, in practice is look for the point position, workbench return to zero after all workpieces processed over, all those points passed by have the problem like path optimization. This control system use two-way scanning method.

\section{Laser and Corollary Equipment for Laser Direct Writing}

Use a new structure dual-wavelength fiber laser[9], the two laser' structure base on two materials $\mathrm{AlGaAs}$ and AlGaInP and active layer, the laser can give out wavelengths $532 \mathrm{~nm}$ and $1537 \mathrm{~nm}$.

Accurate positioning in the three-dimensional system of coordinate, measure the cladding point temperature, use five-axis parallel double beam vibration control technology, achieved the laser direct writing of copper nickle alloy basis plate, multi layer and three dimensional copper nickle alloy plate.

Laser micro cladding lens achieved automatic focusing, use numerically-controlled rotary table achieved complex shape forming, use laser intelligent timer control micro cladding time accurately. 
Use laser power real-time feedback control system solve the problem that the melting point is different because of the different ingredient in the micro cladding copper nickle equipment. Use the mixing techniques consist of laser direct writing, laser chemical vapor deposition, and laser induced liquid phase reaction precipitation, therefor it's needed to control the output power reasonably, achieved the best cladding result. Laser powder control unite use closed-loop control, collecting feedback in real-time, control the parameters like power, speed, pulse width accurately, achieved the optimize for the mixing techniques consist of laser direct writing, laser chemical vapor deposition, and laser induced liquid phase reaction precipitation, achieved the best cladding effect for copper nickle alloy. The laser focus position real-time control system control the copper nickle alloy powder eruption, cladding, control the position of laser focal point in real-time, make the laser focal point on the copper nickle powder all the time, cladding accurately. The equipment use evaluating algorithm base on image definition and upper and lower computer serial communication control stepping motor achieved auto focusing in real-time.

\section{Conclusion}

Use laser direct writing copper nickle alloy technology can manufacture kinds of features of copper nickle alloy used for seawater pipe, include cladding antioxidation coating on the copper nickle alloy, use copper powder and nickle powder manufacture copper nickle alloy, use thermosetting resin as bond system, after laser cladding, can manufacture kinds of features of copper nickle alloy, pipe and shroud, the accuracy can reach $20^{\mu m}$, the minimum width can reach $80^{\mu m}$, the performance improved obviously, with no need for special molding can manufacture tubular copper nickle alloy, spiral copper nickle alloy, coating copper nickle alloy and so on.

\section{References}

[1] Liu Fang Liu Changsheng Chen Suiyuan Tao Xingqi, W2C Reinforced Nickel-based Coating Authigeniced by laser on Copper Alloy Surface, Chinese Journal of Material Research STIC EI PKU -2007 5th.90-93

[2] Dong Jiang Liu Fang Chen Suiyuan Liu Changsheng, Copper laser cladding $\mathrm{Co}-\mathrm{Ni}-\mathrm{Cu}$ gradient coating on copper Board, Journal of Northeastern University(Natural Science), ISTIC EI PKU -2008 11th, 129.

[3] Dong Jiang Liu Fang Chen Suiyuan Liu Changsheng, Ni - Cu laser cladding layer add SiC whisker in copper alloy, ournal of Northeastern University(Natural Science), ISTIC EI PKU -2009 $1 \mathrm{st}, 53$.

[4] Amey Daniel I, Horowitz Samuel J. Materials performance at frequencies up to 20GHz.DuPont Photopolymer \& Electron Materials, 1998:250.

[5] Li Huiling, Zeng Xiaoyan. Influence to antioxidation coating performance of copper nickle alloy made of laser cladding from subsequent sintering, Chinese Journal of Lasers, 2005, 33(1).

[6] LI Guiyun. Low temperature co-firing copper nickel materials system and it's application. Productions and Technologies, 2002, 6:20-24.

[7] Luo Dan, Laser trimming technology for mixed copper nickel alloy material. Hybrid microelectronics technology, 1992, 2(4):14-18, 45.

[8] Wang Tao. Research for $1319^{\mathrm{nm}}$ continuous output Nd: YAG laser. Chinese Journal of Lasers, 2003, 10(3):12-23.

[9] Wang Tao. The Duoble-ended $750 \mathrm{~nm}$ and $532 \mathrm{~nm}$ Laser Output from PPLN-FWM, <Chinese Physs Letters> Vol.30, No6, 2013.064203-1-4. 